\title{
KEANEKARAGAMAN JENIS KUPU-KUPU DI KAWASAN KESATUAN PENGELOLAAN HUTAN (KPH) DESA TIGA BERKAT KECAMATAN LUMAR KABUPATEN BENGKAYANG
}

\author{
(Diversity of butterfly species in Forest Management Unit areas village of Tiga Berkat Lumar \\ sub-district Bengkayang regency)
}

\author{
Dora, Yuliati Indrayani, Iswan Dewantara \\ Fakultas Kehutanan J1. Daya Nasional Pontianak, Telp. 0561764153 kode pos 78124 \\ Email: dorabky@gmail.com
}

\begin{abstract}
Diversity of butterfly species can develop well if in the habitat there are factors that support its population. Protected areas have a higher diversity of butterfly species than those land use conservation area. Beside taking forest product in term of wood or non woody materials, Forest Managemen Unit also provide environmental service such as Clean Water Shelter (PDAM) and Madi Dam. The location of the Madi Dam and Clean Water Shelter are the location that utilized by the communities, this area also have a high diversity of butterfly. The purpose of this study was to obtain data on the diversity of butterflies in the Forest Management Unit in the village of Tiga Berkat lumar sub-district Bengkayang regency. The method used in this research is the transect method. Direct sampling with insect nets is carried out on the transect line. The butterfly found were 28 species with 153 individuals from 4 families are Papilionidae (6 species), Nymphalidae (14 species), Pieridae (6 species) and Lycaenidae (2 species). Diversity index value is 2,98, abundance index value is 0,89 , riches index value is 5,36, dominance index value is 2,14 , species similarity index value is $72,72 \%$.
\end{abstract}

Keywords : Diversity, Butterfly, Forest Management Units

\section{PENDAHULUAN}

Kesatuan Pengelolaan Hutan (KPH) adalah unit pengelolaan hutan terkecil sesuai fungsi pokok dan peruntukkannya yang diharapkan dapat mendukung dan menjamin pengelolaan sumber daya hutan secara efesien dan lestari. Kawasan Kesatuan Pengelolaan Hutan (KPH) yang terletak di Desa Tiga Berkat Kecamatan Lumar Kabupaten Bengkayang memiliki tipe hutan dataran rendah dan dataran tinggi. Selain itu kawasan tersebut memiliki sumber mata air bersih karena masih terdapat hutan lindung di kawasan tersebut dengan tingkat kerapatan tinggi dan memiliki berbagai jenis flora maupun fauna di dalamnya.
Kesatuan Pengelolaan Hutan selain mengambil hasil hutan berupa kayu atau bukan kayu juga menyediakan jasa lingkungan seperti Penampungan Air Bersih PDAM dan Bendungan Madi. Penampungan Air Bersih PDAM ini sangat bermanfaat terhadap kebutuhan air masyarakat sekitar dan Bendungan Madi dibangun di aliran sungai dimanfaatkan oleh masyarakat lokal maupun luar Kota Bengkayang sebagai tempat wisata pemandian. Selain menyediakan jasa lingkungan lokasi ini merupakan ruang terbuka yang mampu menciptakan habitat berbagai satwa, misalnya kupu-kupu. 
$\begin{array}{lll}\text { Menurut } & \text { Koh dan Sodhi } & \text { (2004) } \\ \text { jumlah } & \text { kupu-kupu } & \text { secara }\end{array}$ umumbergantung pada pengelolaan suatu daerah. Daerah yang dilindungi memiliki keanekaragaman spesies kupu-kupu lebih tinggi dari pada daerah yang mengalami alih fungsi lahan. Serangga ini dapat dijadikan indikator perubahan lingkungan karena sifatnya yang rentan terhadap adanya gangguan, sehingga memiliki hubungan yang erat antara keduanya. Keragaman menurun apabila keragaman tumbuhan inangnya menurun. Menurunnya tumbuhan inang dapat terjadi karena aktivitas manusia sehingga lokasi ini perlu diperhatikan dengan baik agar tidak menganggu habitat kupu-kupu didalamnya

Lokasi Bendungan Madi dan penampungan Air Bersih PDAM juga merupakan lokasi yang dimanfaatkan masyarakat, kawasan ini juga berpotensi memiliki keanekaragaman kupu-kupu yang cukup tinggi, akan tetapi pihak pengelola KPH belum ada data tentang keanekaragaman kupu-kupu, sehingga perlu dilakukan penelitian tentang keragaman kupu-kupunya.

Tujuan penelitian ini untuk mendapatkan data keanekaragaman kupukupu di kawasan KPH khususnya di lokasi Bendungan Madi dan Penampungan Air Bersih PDAM. Manfaat penelitian diharapkan dapat memberikan data dan informasi mengenai keanekaragaman kupu-kupu dan dapat mempertahankan jenis kupu-kupu di kawasan KPH.

METODE PENELITIAN

Penelitian dilaksanakan pada kawasan pengelolaan kesatuan hutan $(\mathrm{KPH})$ yaitu disekitar lokasi tempat Penampungan Air Bersih PDAM dan Bendungan Madi Kawasan Kesatuan Pengelolaan Hutan (KPH) di Desa Tiga Berkat Kecamatan Lumar Kabupaten Bengkayang Provinsi Kalimantan Barat. Penelitian dilaksanakan selama 3 minggu dimulai dari tangal $1-21$ juni 2019.

Lokasi tersebut dipilih berdasarkan jenis dan struktur vegetasi yang menyusun di masing-masing lokasi, yaitu adanya tanaman golongan bawah yang terdapat di sepanjang tepian dan/atau areal aliran sungai dimana tanaman tersebut menghasilkan sumber pakan bagi kelangsungan hidup kupu-kupu serta ditinjau dari keterjangkauan lokasi.

Alat dan bahan yang digunakan pada penelitian ini antara lain: Peta lokasi, GPS, Tally sheet, Kamera, Tali rafia, Buku identifikasi, Jaring serangga, Styrofoam, Jarum suntik, Kertas papilot, Penggaris, Alkohol 70\%, Pinset, Cat kuku, Kotak spesimen, dan Termohygrometer.

Metode yang di gunakan dalam penelitian ini yaitu metode transek (Soerianegara, 1988). Pengambilan sampel secara langsung dengan jaring serangga dilakukan pada jalur transek. Prosedur penelitian dengan membuat transek sejajar dengan tepi sungai di sekitar Bendungan Madi (riparian) dan sekitar lokasi Penampungan Air Bersih PDAM (terrestrial) masing-masing panjang garis transek $200 \mathrm{~m}$ dengan jarak pandang ke kanan dan ke kiri $5 \mathrm{~m}$ (Noerdjito dan Puji 2003).

Sesudah membuat garis transek pengamat menjelajah dengan berjalan kaki di lokasi pada pagi hari yaitu pukul 08.00 - 
12.00 WIB dan sore hari pukul 13.00 15.00 WIB berdasarkan waktu aktif terbang kupu-kupu (Erniwati, 2009) dengan kondisi cuaca yang cerah. Setiap lokasi dilakukan pengamatan yaitu dua kali pengulangan. Pengukuran parameter lingkungan hanya meliputi suhu $\left({ }^{0} \mathrm{C}\right)$ dan kelembaban (\%).

Kupu-kupu yang tidak dapat diidentifikasikan pada lokasi penelitian dan kupu-kupu dominan diambil untuk dijadikan koleksi (insectarium). Parameter yang digunakan dalam analisis data meliputi:

\section{Indeks dominansi}

Indek dominansi (C) digunakan untuk menentukan jenis satwa dominan yang ditemukan dilapang dan digunakan rumus Odum (1998) :

$\mathrm{C}=\boldsymbol{\Sigma}\left(\frac{n i}{\mathrm{~N}}\right)^{2}$

Dimana :

$\mathrm{C}=$ indeks dominansi

$\mathrm{ni}=$ jumlah individu suatu jenis

$\mathrm{N} \quad=$ Jumlah Individu Seluruh Jenis

Kriteria menurut Odum (1998)

$\mathrm{C} \leq 0,5=$ tidak terdapat spesies yang mendominansi

$\mathrm{C} \geq 0,5 \quad=$ terdapat spesies yang mendominansi

\section{Indeks keanekaragaman jenis $\left(\mathrm{H}^{\prime}\right)$}

Indeks keanekaragaman jenis adalah indek keseluruhan dalam suatu komunitas di hitung dengan rumus indeks keanekaragaman Shannon wiener Odum (1998) :

\section{$H^{\prime}=-\Sigma$ pi Ln pi}

$\mathbf{P i}=\mathbf{n i} / \mathbf{N}$

Dimana:

$\mathrm{H}^{\prime}=$ indeks keanekaragaman jenis
$\mathrm{Pi} \quad=$ proporsi jenis $-\mathrm{i}$ terhadap total individu semua jenis

$\mathrm{Ni} \quad=$ jumlah individu setiap spesies

$\mathrm{N}=$ total jumlah individu seluruh jenis

Kriteria menurut Magurran (1988)

$\mathrm{H}<1 \quad=$ keanekaragaman rendah

$1<\mathrm{H}<3=$ keanekaragaman sedang

$\mathrm{H}>3$ = keanekaragaman sedang

\section{Indeks kelimpahan jenis $(e)$}

Kelimpahan jenis dipengaruhi oleh keanekaragaman jenis dan jumlah jenis untuk mengetahui indeks kelimpahan jenis digunakan rumus menurut Pielou (Odum, 1998):

$\mathbf{e}=\frac{\mathbf{H}}{\operatorname{Ln} S}$

dimana:

e $\quad=$ kelimpahan jenis

$\mathrm{H}^{\prime} \quad$ = keanekaragamn jenis

$\mathrm{S} \quad=$ jumlah seluruh jenis

Ln = logaritma natural

Kriteria menurut Odum (1998)

$\mathrm{e} \leq 0,4 \quad=$ kelimpahan rendah

$0,4<\mathrm{e}<0,6=$ kelimpahan sedang

$\mathrm{E} \geq 0,6 \quad=$ kelimpahan tinggi

\section{Indeks kekayaan jenis}

Indeks kekayaan jenis merupakan nilai rasio perbandingan antara jumlah jenis keseluruhan terhadap jumlah jenis yang dijumpai pada suatu tipe hutan. Indeks yang digunakan adalah indeks kekayaan Margalef dengan persamaan sebagai berikut:

\section{Dmg $=(\mathbf{S}-\mathbf{1}) / \mathbf{I n} \mathbf{N}$}

Dimana:

Dmg = kekayaan jenis Margalef

$\mathrm{S} \quad=$ total jumlah jenis

$\mathrm{N} \quad=$ jumlah total individu

Kriteria menurut Jorgensen et al (2005)

$>4,0=$ baik 


$$
\begin{array}{ll}
2,5-4,0 & =\text { sedang } \\
<2,5 & =\text { buruk }
\end{array}
$$

\section{Indeks kesamaan jenis}

Indeks kesamaan jenis merupakan jumlah nilai yang menunjukan tingkat kesamaan jenis, yang diperoleh dengan membandingkan 2 komunitas tertentu dapat diketahui menggunakan rumus Magurran(1988) :

\section{$\mathrm{CN}=\mathbf{2} \mathrm{jN} /(\mathrm{aN}+\mathrm{bN}) \times 100 \%$}

Dimana:

$\mathrm{jN}=$ jumlah individu yang sama dan terendah pada dua lokasi yang di bandingkan

aN = jumlah jenis pada lokasi 1

$\mathrm{bN} \quad=$ jumlah jenis pada lokasi 2

kriteria menurut Magurran(1988):

$\mathrm{CN}<50 \%=$ tidak sama
$\mathrm{CN}>50 \%=$ sama

\section{HASIL DAN PEMBAHASAN}

\section{Jumlah Jenis Kupu-Kupu}

Jumlah total jenis kupu-kupu yang ditemukan di kawasan hutan KPH bengkayang khususnya di lokasi Penampungan Air Bersih PDAM dan Bendungan Madi sebanyak 28 jenis dengan jumlah individu 153 individu. Kupu-kupu yang ditemukan termasuk kedalam famili Papilionidae, Nymphalidae, Pieridae dan Lycaenidae, Famili Nymphalidae merupakan famili dengan jumlah jenis dan individu paling banyak dan penyebaran luas dibandingkan dengan famili lainnya (Smart, 1975). Jenis kupu-kupu yang di temukan pada kawasan hutan KPH Bengkayang di sajikan pada Tabel 1.

Tabel 1. Jumlah total individu kupu-kupu pada kawasan hutan KPH Bengkayang (The total number of individual butterfly in the forest area KPH bengkayang)

\begin{tabular}{ccc}
\hline No Famili & jenis kupu-kupu & jumlah individu kupu-kupu \\
\cline { 2 - 3 } & di PDAM & di B. Madi \\
\hline 1.Papilionidae Graphium sarpedon & 5 & 4 \\
Graphium evemon & - & 4 \\
Papilio memnon & 1 & 2 \\
Papilio polytes & 4 & 3 \\
Neorina lowii neophyte & 5 & - \\
Papilio demoleus & 2 & 2 \\
2. NymphalidaeLexias pardalis & 4 & 4 \\
Athyma pravara & 2 & 2 \\
Parantica agleoides & - & 3 \\
Hypolimnas bolina & 3 & 4 \\
Euploea radamanthus & - & 1 \\
Tanaecia & 5 & - \\
Cirrochroa Malaya & - & 1 \\
Danainae sp. & - & 2 \\
Rohana macar & - & 1 \\
Celaenorrhinus aurivittata & - & 1 \\
Vidula Erota & 1 & 2 \\
Bicycles sandace & 2 & - \\
Mycalesis mineus & 2 & - \\
Ypthima pandocus & 1 & -
\end{tabular}




\begin{tabular}{cll} 
3. Pieridae $\quad$ Cepora nerissa & 2 & 5 \\
Eurema sari & 21 & 4 \\
Gandaca harina & 5 & 2 \\
Cepora Judith & 2 & 3 \\
Hebomoia glaucipe & 2 & 2 \\
Leptosia nina & 2 & 3 \\
Zizina otis & 4 & 2 \\
4. Lycaenidae Jamides alecto & 16 & 4 \\
\hline Jumlah individu & $\mathbf{9 1}$ & $\mathbf{6 2}$ \\
Jumlah jenis & $\mathbf{2 1}$ & $\mathbf{2 3}$ \\
\hline
\end{tabular}

Sumber: Jumlah Total Kupu-kupu ditemukan di lapangan

Jenis Eurema sari merupakan kupukupu yang paling banyak ditemui pada lokasi Penampungan Air Bersih PDAM sedangkan di lokasi Bendungan Madi yaitu jenis Cepora nerissa. Perbedaan jumlah individu pada kedua lokasi ini dipengaruhi oleh sumber pakan kupukupu. Setiap jenis kupu-kupu memiliki kesukaan tersendiri terhadap jenis tumbuhan inang. Kupu-kupu jenis Eurema sari banyak mengujungi tanaman Posor (Pseuderanthemum diversifolium) penyebaran tanaman ini banyak di Penampungan Air Bersih PDAM, sedangakan di Bendungan Madi banyak tanaman rambatan (Mikania micrantha) yang merupakan pakan kupu-kupu Cepora nerissa. Banyaknya kupu-kupu pada suatu daerah dipengaruhi oleh penyebaran dan banyaknya tumbuhan pakan dimana, keberadaan kupu-kupu sangat bergantung pada tumbuhan pakannya, baik sebagai inang bagi larva maupun sebagai sumber nektar bagi imago (Rahayu, 2012).

\section{Keanekaragaman dan Dominansi jenis kupu-kupu}

Tabel 2. Hasil analisis Keanekaragaman dan Dominansi jenis kupu-kupu (Results of analysis Diversity and Dominance butterfly species)

\begin{tabular}{lcccc}
\hline \multicolumn{1}{c}{ Lokasi } & Jumlah jenis & Jumlah individu & H' & C \\
\hline PDAM & 21 & 91 & 2,62 & 0,11 \\
Bendungan Madi & 23 & 62 & 3,00 & 0,05 \\
\hline Jumlah Total & & & 5,62 & 0,16
\end{tabular}

Keterangan : $\mathrm{H}=$ Keanekaragaman jenis $\mathrm{C}=$ Dominansi jenis

Hasil perhitungan indeks

keanekaragaman dan dominansi jenis kupu-kupu pada kawasan hutan KPH bengkayang yang terdapat pada dua lokasi penelitian dengan nilai jumlah total keanekaragaman sebesar 2,98 nilai ini menunjukan indeks keanekaragaman sedang karena kriteria menurut Odum
(1998) bahwa nilai 1 - 3 termasuk sedang. Nilai rata-rata dominansi seluruh jenis kupu-kupu pada kawasan hutan KPH bengkayang adalah 2,14 nilai tersebut menunjukkan bahwa terdapat jenis yang dominan, karena apabila nilai dominansi $\geq 0,50$ dikatakan ada kupukupu yang mendominan (Odum, 1998). 


\section{Kekayaan dan Kelimpahan jenis kupu-kupu}

Tabel 3. Hasil analisis Kekayaan dan Kelimpahan jenis kupu-kupu (Results of analysis Riches and Abundance butterfly species)

\begin{tabular}{lcccc}
\hline Lokasi & Jumlah jenis & Jumlah individu & D & e \\
\hline Penampungan Air Bersih PDAM & 21 & 91 & 4,43 & 0,86 \\
Bendungan Madi & 23 & 62 & 5,33 & 0,96 \\
\hline Jumlah Total & & & 9,76 & 1,82 \\
\hline
\end{tabular}

Keterangan : $\mathrm{D}=$ Kekayaan jenis e = Kelimpahan jenis

Hasil perhitungan dapat diketahui tingkat kekayaan jenis kupu-kupu pada kawasan hutan KPH Bengkayang khususnya pada lokasi Penampungan Air Bersih PDAM dan Bendungan Madi dengan nilai jumlah total 5,36 Menurut kriteria Jorgensen et al (2005) nilai indeks kekayaan jenis kupu-kupu tergolong baik karena rentang nilai $>4,00$ tergolong baik. Indeks kelimpahan jenis kupu-kupu pada dua lokasi penelitian senilai 0,90 Nilai ini menunjukkan bahwa jenis kupu-kupu pada dua lokasi tergolong tinggi karena kriteria menurut Odum (1998) bahwa nilai $\geq 0,60$ tergolong tinggi.

\section{Kesamaan jenis kupu-kupu}

Tabel 4. Hasil analisis Kesamaan jenis (Results of species Similarity analysis)

\begin{tabular}{lcc}
\hline Lokasi & Jumlah jenis yang sama & CN \\
\hline $\begin{array}{l}\text { Penampungan Air Bersih PDAM- } \\
\text { Bendungan Madi }\end{array}$ & 16 & $72,72 \%$ \\
\hline Kerngan $:$ C $~$ & & \\
\hline
\end{tabular}

Keterangan : $\mathrm{CN}=$ Kesamaan jenis

Berdasarkan hasil perhitungan, indeks kesamaan jenis antar kedua lokasi penelitian yaitu di lokasi Penampungan Air bersih PDAM dan Bendungan Madi memiliki nilai $72,72 \%$ nilai ini menunjukanbahwa kesamaan jenisnya tergolong tinggi menurut Magurran (1988) karena rentang kriteria $\mathrm{CN}>50 \%$ tergolong tinggi.

Kesamaan jenis antara Penampungan Air bersih PDAM dengan Bendungan Madi ditemukan 16 jenis kupu-kupu yang sama yaitu Graphium sarpedon, Papilio memnon, Papilio polytes, Lexias pardalis, Papilio demoleus, Athyma pravara, Hypolimnas bolina, Vidula Erota, Cepora nerissa, Eurema sari, Gandaca harina, Cepora Judith, Hebomoia glaucipe, Leptosia nina, Jamides alecto, Zizina otis.
Tingginya indeks kesamaan pada kedua lokasi penelitian disebabakan oleh area tersebut mampu menyediakan sumber daya yang dibutuhkan bagi kehidupan kupu-kupu. Kelimpahan relatif sumber daya tumbuhan pakan yang dibutuhkan kupu-kupu memberikan pengaruh yang sangat signifikan terhadap kelimpahan relatif jenis konsumennya (Yamamoto et al, 2007).

Selain sumber pakan tingginya indeks kesamaan jenis juga dipengaruhi oleh suhu dan kelembaban pada lokasi. Organismeorganisme dan lingkungan berhubungan erat tak terpisahkan dan saling mempengaruhi satu sama lain (Odum, 1998). 
JURNAL HUTAN LESTARI (2019)

Vol. 7 (3) : 1461 - 1469

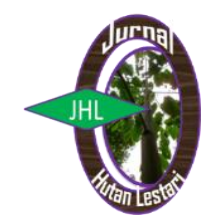

Dokumentasi Jenis Kupu-Kupu

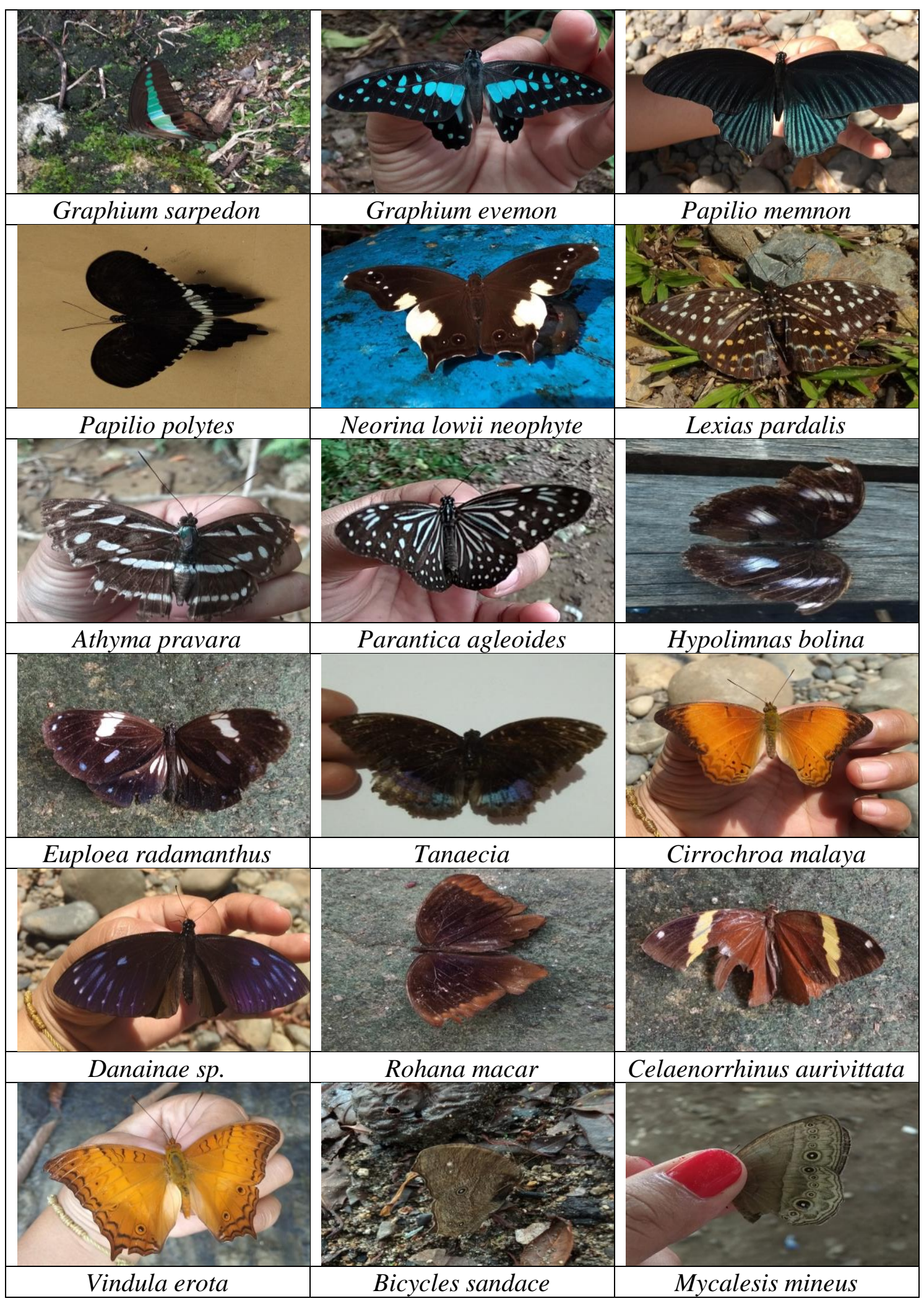




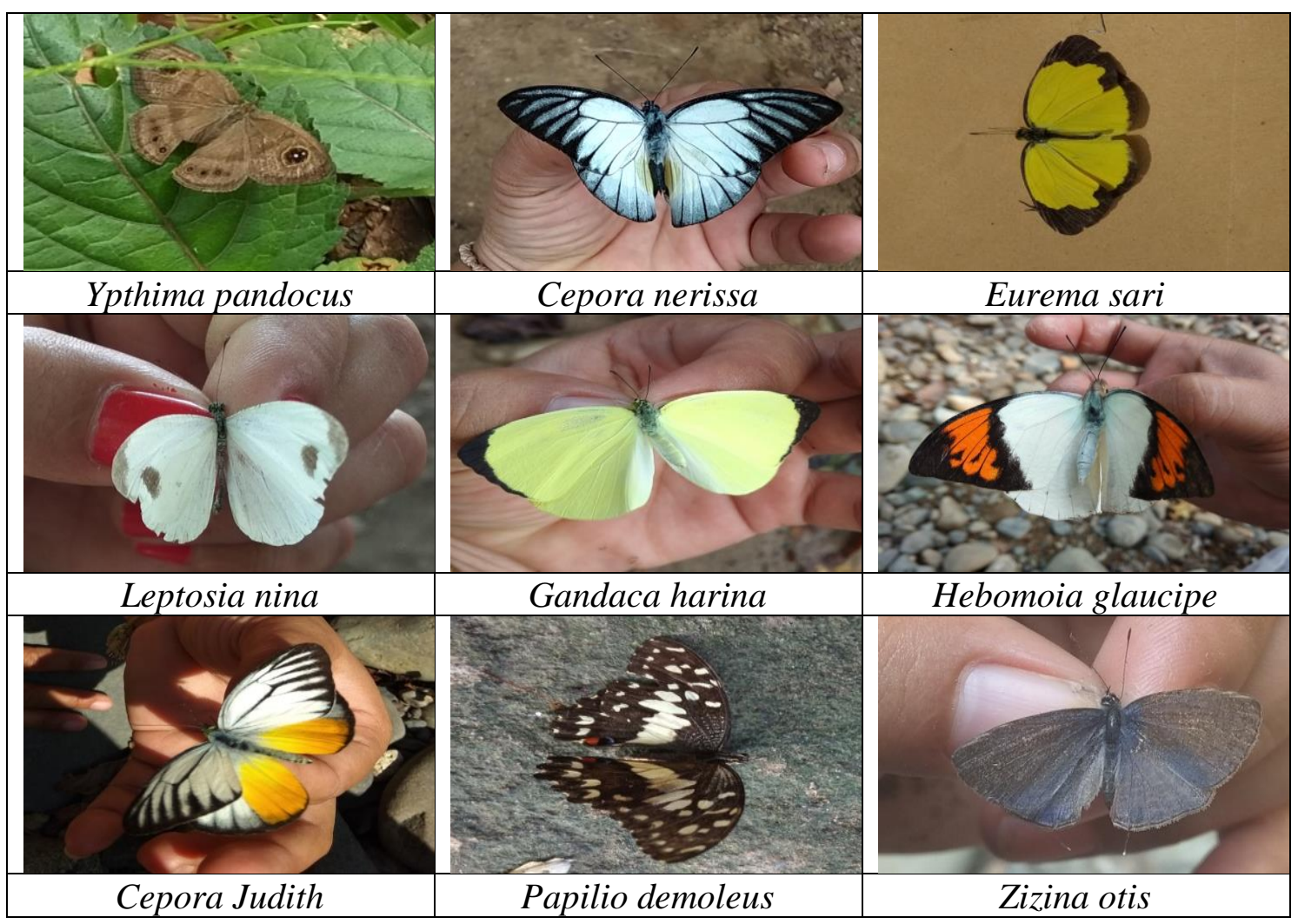

\section{KESIMPULAN}

Kupu-kupu yang ditemukan khususnya di lokasi Penampungan Air Bersih PDAM terdapat 21 jenis dengan jumlah individu 91 sedangkan di lokasi Bendungan Madi terdapat 23 jenis dengan jumlah individu 62. Total kupukupu yang ditemukan pada kawasan hutan KPH Bengkayang khususnya di Penampungan Air Bersih PDAM dan Bendungan Madi terdapat 28 jenis dengan jumlah individu 153 individu dari empat famili yaitu Papilionidae (6 jenis), Nymphalidae (14 jenis), Pieridae (6 jenis) dan Lycaenidae (2 jenis). Famili paling banyak dijumpai yaitu famili Nymphalidae.

Nilai indeks keanekaragaman sebesar 2,98, nilai indeks kelimpahan sebesar 0,90 , nilai indeks kekayaan jenis
5,36 . Nilai indeks dominansi yaitu 2,14 yang menunjukan bahwa ada jenis yang dominan. Nilai indeks kesamaan jenis yaitu Penampungan Air Bersih PDAM dan Bendungan Madi 72,72\%.

Terdapat 16 jenis kupu-kupu yang sama yaitu Graphium sarpedon, Eurema sari, Papilio polytes, Papilio memnon, Lexias pardalis, Zizina otis, Jamides alecto, Leptosia nina, Hebomoia glaucipe, Cepora Judith, Gandaca harina, Cepora nerissa, Athyma pravara, Hypolimnas bolina, Vidula.

\section{DAFTAR PUSTAKA}

Bibas E, Ahmad M, dan Desita S. 2016. Keanekaragaman kupu-kupu di kawasan Gunong Bonsu Kabupaten Rokan Hulu, Provinsi Riau. Jurnal Riau Biologia, 1(6): 39 
Erniwati. 2009. Keanekaragaman dan Sebaran Serangga di Kawasan Pulau-Pulau Kecil Taman Nasional Karimunjawa. Berita Biologi 9(4): 349-35

Koh KP, NS Sodhi. 2004. Importance of Reverse, Fragments And Parks For Butterfly Conservation In A Tropical Urban Lanscape. Ecological Applicaton.

Magurran, A. E. 1988. Ecological Diversity and Measurement. New Jersey: Princetown University Press

Noerdjito WA, Aswari P. 2003. Metode Survei dan Pemantauan Populasi Satwa: Seri Ke-empat Kupu-kupu Papilionidae. Bogor: Bidang Zoologi, Pusat Penelitian BiologiLIPI.

Odum EP. 1998. Dasar - Dasar Ekologi. Edisi Ke-3, Terjemahan Tjahjono
Samingan.Gadjah Mada University Press. Yogyakarta.

Odum EP. 1971. Fundamental Ecology, $3^{\text {rd }}$ Edition, Toppan Company, Ltd. Tokyo.

Rahayu, SE, Adi, B. 2012. Kelimpahan dan Keanekaragaman Species Kupu-kupu (Lepidoptera): Rhopalocera pada Berbagai Tipe Habitat di Hutan Kota Muhammad Sabki Kota Jambi. Jurnal Biospecies, 5(2): 40-48.

Soerianegara .1988.Ekologi Hutan Indonesia. Bogor: Laboratorium Ekologi Hutan Fakultas Kehutanan. Institute Pertanian Bogor.

Yamamoto N J, Yokoyama, M Kawata. 2007. Relative resource abundance explains butterfly biodiversity in island communities. PNAS.104 (25): 10524-10529. 